\title{
Metacognitive Strategy Training Adds to the Effects of Working Memory Training in Children with Special Educational Needs
}

\author{
Petri Partanen ${ }^{1}$, Billy Jansson ${ }^{1}$, Jan Lisspers ${ }^{1} \&$ Örjan Sundin ${ }^{1}$ \\ ${ }^{1}$ Department of Psychology, Mid Sweden University, Östersund, Sweden \\ Correspondence: Petri Partanen, Department of Psychology, Mid Sweden University, Östersund, 83125, Sweden. \\ E-mail: petri.partanen@miun.se
}

Received: June 30, 2015 Accepted: August 10, 2015 Online Published: August 12, 2015

doi:10.5539/ijps.v7n3p130 URL: http://dx.doi.org/10.5539/ijps.v7n3p130

\begin{abstract}
The effects of computer-based Working Memory (WM) training using two training procedures were examined among sixty-four primary-school children with Special Educational Needs (SEN). Measures of general cognitive ability, auditory and visuospatial working memory, arithmetic ability, and reading and writing skills were gathered and analysed. The referred group of SEN children predominantly had lower performance in auditory WM, arithmetics and reading and writing skills. The SEN children within respective school were randomized into either an active WM training group or a control group and ten schools participating in the WM training study were randomized into one of two different training conditions. At five schools the SEN children received regular WM training and at the other five schools the children received WM training with the addition of metacognitive strategy training. Results showed a significant difference in WM performance during training in favor of the metacognitive intervention. Furthermore, transfer effects occurred on visuospatial WM measures at posttest and at 6-month follow-up. Post-hoc tests showed that the effects pertained only to the metacognitive intervention. No transfer to arithmetic or reading and writing skills occurred after training in the two training conditions. Results were discussed in terms of metacognitive factors being important in optimizing performance in WM training, and that such factors should be taken into consideration when designing interventions for children with SEN. It is also suggested that in referral of children with SEN to remediation with WM training the WM profiles should be taken into consideration to a greater degree.
\end{abstract}

Keywords: children with special educational needs, metacognitive strategy training, working memory training

\section{Introduction}

There are a number of situations in everyday life where Working Memory (WM) is hypothesized to play a crucial role, such as listening to instructions, solving a math problem, reading a text, carrying out a plan. All these situations require the ability to retain and execute information. Working memory refers to important cognitive processes involved in one's ability to retain information for a short period and use it after a delay (e.g., Baddeley, 1986, 2007). In the original Baddeley model of working memory three components are described: a visuospatial and a phonological component responsible for temporary storage of short-term information, and a central executive responsible for more elaborate processing of the information.

Subsequent research on WM has focused on the relation between simple temporary memory storage and more complex executive attention processes. For example, the attentional control model (Engle \& Kane, 2004) argues that working memory capacity can be explained by differences in executive attention primarily. The embedded process model (Cowan, 2012) advocates that WM should be understood as embedded processes involving both long-term memory representations that are activated in tasks, and focus of attention that makes activated items salient. For a more detailed review of different WM models used in educational context see Fenesi, Sana, Kim and Shore (2014). In a review it was concluded that storage and more complex processing components in WM are strongly related to one another, with both shared and unique variance attributed to them (Unsworth, Redick, Heitz, Broadway, \& Engle, 2009).

In school context WM has been addressed as a crucial cognitive function underlying learning difficulties for children with special educational needs (SEN) (Alloway, Gathercole, Adams, \& Willis, 2005). Previous research on the relation between WM and school related abilities has shown that low WM performance has negative consequences for the progress of reading, mathematics as well as language and reading comprehension 
(Passolunghi \& Siegel, 2001; Signeuric, Ehrlich, Oakhill, \& Yuill, 2000; Swanson, 1994; Swanson, Howard, \& Sáez, 2006). Reversely, Pickering and Gathercole (2004) has also studied children with SEN and found that many of these children perform poorly on measures of complex memory, including WM.

Several studies concerned with computer-based WM training programs have shown a significant improvement on WM in preschool and school children (Holmes, Gathercole, \& Dunning, 2009; Morrison \& Chein, 2010; Thorell, Lindqvist, Bergman, Bohlin, \& Klingberg, 2009), particularly among children with ADHD (Holmes et al., 2010; Klingberg, Forssberg, \& Westerberg, 2002). Research also suggests that the effects following computer-based WM training transfer to school related skills, such as mathematics and reading comprehension (Dahlin, 2010; Holmes et al., 2009). However, a meta-analysis (Melby-Lervåg \& Hulme, 2012) has challenged the notion of the effectiveness of WM training and its enhancing effect on cognitive functions in typically developing children. The authors concluded that WM training produces only short-term training effects that do not sustain over time and do not transfer to subject areas.

According to Holmes et al. (2009), a majority of children being subject to WM training reported that they had used a number of different strategies in order to improve the training. These authors concluded that "training may indeed enhance attentional focus and stimulate a whole set of strategies that can be flexibly deployed with generalized benefits in a wide range of activities that place heavy demands on WM" (p. 14). How these strategies can be operationalized, how they develop and can be systematically enhanced, and which effects they have on cognitive performance during computer-based training needs to be clarified.

Studies have shown that strategy training by using rehearsal, imagery and semantic coding strategies has a positive effect on working memory performance (Caretti, Borella, \& De Beni, 2007; McNamara \& Scott, 2001; Turley-Ames \& Whitfield, 2003). Related to this, research has also shown that working memory performance can be enhanced by metacognition. For example, Whitebread (1999) showed that the relationship between working memory capacity and cognitive performance was dependent upon metacognitive abilities. Also, Autin and Crozet (2012) demonstrated that, by addressing children's metacognitive interpretation of a particular task, the working memory span improved. The effects of metacognitive training among children with special needs (low achievers/learning difficulties) has been examined in computer-based and regular learning environments, yielding positive effects on mathematical problem-solving (Mevarech, 1999; Teong, 2003) and on general problem-solving (Borkowski, Estrada, Milstead, \& Hale, 1989). It has also been suggested (Passolunghi \& Siegel, 2004) that problem-solving performance is related to the ability of reducing the accessibility of irrelevant information in memory, and thereby increasing the possibility of retaining new information.

A number of researchers and practitioners in the field of cognitive education have developed principles and frameworks for metacognitive training in educational settings. Metacognitive interventions in form of structured guided interactions between the teacher and children are expected to create prerequisites for generalization and transfer from cognitive training to specific cognitive functions (e.g., working memory, executive functioning) and to general cognitive functioning, (Das, 1999; Das, Naglieri, \& Kirby, 1994; Feuerstein, Rand, Hoffmann, \& Miller, 1980, 2004; Tzuriel, Kaniel, Kanner, \& Haywood, 1999). However, there is a need to further study effects of metacognitive strategy training in relation to cognitive functions in school settings.

Cognitive strategies could be viewed as domain- or task-specific strategies (e.g., elaboration, rehearsal, organization strategies) for dealing with the tasks at hand (Boer, Donker-Bergstra, \& Kostons, 2013). Metacognitive strategies consist of monitoring strategies used in different phases of the learning-from planning a task to the execution of the task, and to the summarization and evaluation after the completion of the task. The metacognitive strategies are higher-order thinking strategies that involve self-reflection, self-questioning and evaluation, leading to a formulation of metacognitive knowledge (Flavell, 1976, 1979). A recent meta-analysis (Boer et al., 2013) has pointed out the importance of redirecting the child from using more domain-specific task-oriented cognitive strategies to using more metacognitive and self-regulatory strategies. Similarly it has been suggested that training metacognitive strategies is more effective than training fewer and/or simpler rule-based cognitive mnemonic strategies (Hattie, Biggs, \& Purdie, 1996). Thus, when creating metacognitive training procedures, a broad range of metacognitive strategies should be employed.

In this study, children in primary school were identified as having special educational needs (SEN) and were referred to WM training. We initially examined the profiles of cognitive functioning, arithmetic ability, reading/writing skills and especially the variability of WM functioning in this typical referred sample of SEN children. We also compared arithmetic ability and reading/writing skills between groups with low and normal WM functioning.

By adopting a prospective and quasi-experimental design, the main purpose of this study was to examine the 
effects of standard WM training and WM training with the addition of metacognitive strategy training. We hypothesized that a training framework that incorporates metacognitive strategy training will improve the immediate training effects (as measured by the levels of cognitive performance during training) compared to a training program that follows standard procedures for WM training. In addition, we examined if there are transfer effects from cognitive training to WM tasks, general cognitive ability, arithmetic ability, and to reading and writing skills.

\section{Method}

\subsection{Design and Participants}

Ten participating primary schools in a midsized (approx. 50,000 inhabitants) municipality in Sweden were randomly assigned to two groups: five schools carried out standard WM training and five schools carried out WM training with the addition of metacognitive strategy training lessons (MC). In each school, children (second and third grade) with SEN were subsequently randomized into a training group or a wait-list control group, in order to create an even distribution with respect to age. The children $(N=67)$ were selected based on functional criteria commonly used in Sweden when identifying special educational needs. Specifically, they were identified on basis of their observed behavioral need of support in areas of planning, attention and working memory, and in correspondence with the recommendations provided by the WM training program used (Cogmed, 2009).

One child dropped out before the training and two children did not meet the minimum training criteria of 20 training days and were therefore excluded from the study. Following randomization, the standard WM group consisted of 20 children, 6 girls and 14 boys, with a mean age of 8.61 years $(S D=.51)$. WM training with addition of metacognitive strategy training (MC) consisted of 20 children, 20 boys, with a mean age of 8.66 years $(S D=.50)$. The control group consisted of 24 children, 6 girls and 18 boys, with a mean age of 8.41 years $(S D=.57)$. The study was reviewed and approved by the regional ethics committee.

\subsection{Measures}

General cognitive nonverbal reasoning ability was measured with Ravens Coloured Progessive Matrices (Raven, 1995) and Block design from WISC-III (Wechsler, 1991) both standardized and norm-referenced tests. In Ravens the child is asked to identify a missing element that completes a pattern, out of six response options that are displayed in a booklet. The tasks are of increasing and varying complexity and untimed. In Block Design the child is asked to put together red and white blocks in a pattern according to a displayed model, with increasing complexity. The tasks are timed and the child is allowed to work until a specified level of omissions.

Auditory WM was measured with Digit span (Wechsler, 1991). The digit span task requires the child to listen to a sequence of digits and then repeat the proper order, with increasing level of difficulty until the child reaches a threshold. The digit span task is administered forwards and backwards. Visuospatial WM was measured with Spatial span test (Wechsler, 2006), where the assessor taps out progressively longer sequences of block patterns on a three-dimensional plate consisting of nine blocks, and the child is asked to repeat the sequence by pointing at the blocks in the correct order. The Spatial span test is similarly administered both forwards and backwards. The WM measures consist of number of correct responses, while Raven Matrices and Block design follow standardized scoring procedures, until the child reaches a consistent level of omissions, indicating a threshold.

Forward as well as backward processing measures were used from the WM measures, since research has indicated that forward and backward processing are different but related processes. While forward processing and immediate recall could be interpreted as measures related to short term memory retention, tasks including backward processing can be considered to also include more complex higher-order cognitive processing and executive functioning (Alloway, Gathercole, \& Pickering, 2006; Kail \& Hall, 2001).

Arithmetic ability was measured using the Arithmetics test from WISC-III (Wechsler, 1991) and consists of arithmetic problems similar to those encountered in elementary math courses. Problems are administered orally and must be correctly solved mentally within a time limit, without paper and pencil. The Arithmetics test follows standardized scoring procedures until the child reaches a consistent level of omissions, indicating a threshold.

Reading and writing skills were measured with DLS [Diagnostics of reading and writing abilities], a Swedish norm-referenced screening instrument of reading and writing abilities (Järpsten \& Taube, 1997). DLS consists of four subtests measuring reading comprehension, phonological ability, word comprehension and spelling ability.

A standardized measure of WM performance $(M=100, S D=15)$ during training was calculated by the computer-based WM training program (Cogmed, 2009). The initial level of WM performance was calculated during the two first days of training on a number of tasks in the computer-based training program (Training Index time 1). The maximum WM performance during training was calculated during two days at the end of the 
training period on a number of tasks (Training Index time 2). The inclusion of these WM performance measures in the analysis was motivated by the fact that they measure the progress during the intervention, which, in turn, should explain the transfer effects between training and the control condition.

Cognitive and arithmetic data (at pretest, posttest and 6-month follow-up) was gathered by psychologists. Special education teachers gathered the reading and writing skills data. All testing was done in individual settings at the schools.

\subsection{Procedure}

\subsubsection{The WM Training}

A special education teacher at each school supervised the computer-based WM training. Prior to the training period, the special education teacher participated in a one-day education comprising working memory and the training program. The WM training program used was Cogmed WM training (Cogmed, 2009), an established and well-researched computer-based training program consisting of tasks designed as computer games, training different skills related to working memory (Klingberg, 2010). The tasks included are visuospatial and auditory memory tasks embedded in computer games. The central principle in the tasks is that the child is presented with a sequence (for example of visual objects lighting up or auditory information) that the child is asked to reproduce via mouse-click on a subsequent display. Twelve of fourteen tasks are predominantly in visuospatial modality. Tasks involve forward and backward WM processing and varying distractors in form of for example rotating objects. Two tasks adress auditory WM in form of letter and number sequence identification. The program adjusts for the level of difficulty continuously during the training based on the childs' progression. Thus the children are required to perform at the limit of their capacity. For a more detailed account of the type of WM tasks in the training program, see Klingberg, Forssberg and Westerberg (2002).

The computer-based training sessions were conducted approximately 45 minutes every weekday during five weeks in a small group setting with 3 to 5 children. The children were individually seated at the computer with headphones in order not to disturb each other during the training.

\subsubsection{Metacognitive Strategy Training}

The special education teacher working with WM training with addition of metacognitive strategy training (MC) received one day of education on working memory and the training program, and an additional day of education on metacognition and practical training on metacognitive strategy training. Three times a week, after the computer-based WM training session, the special education teacher engaged the group of children in a semi-structured metacognitive strategy-training lesson organized as a group dialogue lasting approximately 45 minutes. The metacognitive lessons began with a specific task from the computer-based training program displayed visually on a printout for the children as a stimulus for exploration and dialogue. This procedure was done in order to prevent exposure to an active WM training condition prior to the actual WM training, and to engage the children in a reflective dialogue addressing their experiences from the WM training session.

During the metacognitive strategy-training lesson, the special education teacher together with the group of children explored the printed stimulus from the computer-based WM training. The special education teacher followed a semi-structured guide, and was encouraged to use questions as prompts to facilitate reflections on cognitive and metacognitive strategies in the group of children. Each lesson focused on five principal activities: the children were asked to (1) label the central objects and elements in the tasks in order to establish a common language (labelling). Typical labelling questions asked by the teacher were "What do you see here in this task? What can you call the different things you see?" Feuerstein, Rand, Hoffmann and Miller $(1980,2004)$ describes the use of precise labels to facilitate effective cognitive processing of information.

The children were further asked to (2) formulate the goal of the specific WM training task (goal-formulation). Typical questions asked by the teacher were "What is the task about? What are you expected to do? What is the goal here?" Analysing the goal of a task is an important part of preparing for strategy identification and self-monitoring (Hattie, Biggs, \& Purdie, 1996). The children were then asked to (3) identify and formulate strategies for both success and failure on the task (cognitive strategies). Typical questions raised could be "How can you succeed in this specific task? What strategies can be important? What should you avoid?"

Furthermore, the children were (4) asked to share and summarize important planning and execution strategies to self-monitor during training (planning and metacognitive strategies). Typical questions could be "How can you plan for this task? How can you prepare yourself? How can you be attentive/endure?" Engaging in planning, self-monitoring and metacognitive reflection has been described in several studies as important in learning (Das, Naglieri, \& Kirby, 1994; Naglieri \& Johnson, 2000). Finally the children were invited to (5) reflect on the 
relation between the tasks in the WM training and situations outside training context in order to facilitate transfer to areas of school learning or leisure time (transfer). Questions asked during this final part of the lesson were: "This task, what might it be good for? Does it remind of something in school or at leisure time? In what way could you use what you learn in the training?"

\subsection{Statistics}

Cutoff scores for the nine measures defining low performance were defined as follows: in Raven Coloured Progressive Matrices a score below the 10th percentile, (equaling 81 in standard score) was set as a criterion to define low performance in general cognitive ability. This is a more strict definition than in the Raven manual (Raven, 1995) but a widely used cutoff in research (Wechsler, 1991; Mayes, Calhoun, \& Crowell, 1998; Fletcher et al., 1998). Similarly, for Block design, Digit span, Spatial span and Arithmetics a scaled score of 6 was set as a cutoff for low performance, equaling a standard score below 81 (Wechsler, 1991, 2006). For the reading and writing skills subtests measuring reading comprehension, phonological ability, word comprehension and spelling ability cutoff for low performance was set to stanine score 2 , following the recommendations in the manual for DLS (Järpsten \& Taube, 1997).

In order to determine whether the mean scores for the group as a whole differed significantly from the standardization sample means for the different measures, a series of one-sample t-tests were performed. The effect size for each measure was calculated with Cohen's $d$. Percentiles, scaled scores and stanine scores were used respectively for the different measures in the calculation. Cohen (1988) defined the magnitudes of effect sizes as follows: small, $d=0.2$, medium, $d=0.5$, and large, $d=0.8$.

Likelihood ratios were calculated for the measures where the referred group of SEN children performed significantly lower. A likelihood ratio is calculated by taking the proportion of participants in the specific group of study that score at a set criterion on a test and comparing it to the proportion of participants in the normal population who score at this level.

Children with low WM were defined as children who performed low on auditory or visuospatial WM or both. In order to compare children with low and normal WM on general cognitive ability, problem solving ability, arithmetics and reading and writing skills, separate ANCOVAs on raw scores were conducted for each measure except the working memory measures, controlling for age as a covariate. Descriptive statistics for children in the whole sample on the nine principal measures are shown in Table 1.

When analyzing effects of the computer-based WM training, ANCOVAs were used to index change from pre-test to post-test and follow-up, while simultaneously controlling for pre-intervention levels. Post-hoc analyses were conducted using Sidak pair-wise comparisons in order to determine significant differences between groups. Data for two participants from the WM group were excluded due to not reaching the minimum 20 training days as recommended. The two training groups did not differ with respect to days of training $(p>.27)$.

Table 1. Descriptive statistics

\begin{tabular}{|c|c|c|c|c|c|c|c|c|c|c|c|c|}
\hline & \multicolumn{4}{|c|}{ Total sample $(n=64)$} & \multicolumn{2}{|c|}{$\begin{array}{c}\text { Low } \\
\text { performance }\end{array}$} & \multicolumn{2}{|c|}{$\begin{array}{c}\text { Low WM } \\
\text { perf. }(n=31)\end{array}$} & \multicolumn{2}{|c|}{$\begin{array}{l}\text { Normal WM } \\
\text { perf. }(n=33)\end{array}$} & \multicolumn{2}{|c|}{$\begin{array}{l}\text { Low vs Nor- } \\
\text { mal WM perf }\end{array}$} \\
\hline & Mean & $S D$ & $p$ & $d$ & $\begin{array}{l}\text { Percent } \\
\quad(n) \quad 1\end{array}$ & $\begin{array}{l}\text { Likeli- } \\
\text { hood ratio }\end{array}$ & $M$ & $S D$ & $M$ & $S D$ & $p$ & $\eta^{2}$ \\
\hline iven matrices ${ }^{\mathrm{a}}$ & 50.23 & 29.13 & .949 & 0.01 & $14(9)$ & - & 44.52 & 29.11 & 5.61 & 28.55 & .061 & .056 \\
\hline lock design ${ }^{b}$ & 9.47 & 3.09 & 173 & 6 & ) & - & 8.90 & 0 & 0 & 2.93 & .168 & .031 \\
\hline igit span ${ }^{b}$ & 7 & 1.89 & .000 & 1.43 & $38(24)$ & 4.22 & 6.19 & 1.60 & 8.33 & 1.53 & 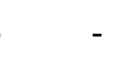 & \\
\hline & 9 & 2 & .14 & 8 & ) & - & 8.85 & 2 & נו.J & 2.62 & - & \\
\hline Arithmetics $^{\mathrm{b}}$ & 6.66 & 67 & .000 & 1.25 & $42(27)$ & 4.67 & 5.39 & 25 & 7.8 & 2.25 & .000 & .235 \\
\hline eading abilit & 2. & 1.71 & .000 & 1.65 & $67(43)$ & 6.09 & 2.35 & 1.92 & 2.00 & 1.50 & .869 & .000 \\
\hline Phonological ability ${ }^{\mathrm{c}}$ & 2 & 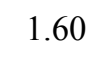 & .0 & 4 & 2) & ) & 2. & 1.53 & 2 & 1.68 & .151 & .034 \\
\hline Word comprehension $^{\mathrm{c}}$ & 3.55 & 1.76 & .000 & 0.82 & $36(23)$ & 3.27 & 3.26 & 1.77 & 3.82 & 1.74 & .194 & .028 \\
\hline Spelling ability ${ }^{\mathrm{c}}$ & 2.80 & 1.62 & .000 & 1.36 & $52(33)$ & 4.73 & 2.71 & 1.56 & 2.88 & 1.67 & .274 & .020 \\
\hline
\end{tabular}




\section{Results}

As Table 1 shows the SEN children performed significantly lower on the auditory WM task compared to a normal age relevant population. Furthermore the group showed significantly lower ability on arithmetics as well as on all four measures of reading and writing. There were large effect sizes for word comprehension, arithmetic's, spelling ability, phonological ability and reading comprehension, ranging from 0.82 to 1.65 standard deviations below the average expected levels for age.

In contrast to the auditory WM performance, no significant differences were found between the referred sample of SEN children and normal population on visuospatial WM tasks. In the areas of general cognitive and problem-solving ability the SEN group performed at levels close to the population mean. No significant differences were found and effect sizes were negligible.

When inspecting the likelihood ratios the SEN children were 4.22 times more likely to obtain low scores on auditory WM, and 4.67 times more likely to perform low arithmetics scores. On the reading and writing skills measures the incidence of low performance ranged from 3.27 to 6.09 times higher than in a standardized normal population sample. After adjustment for age, there was a significant difference only in arithmetic ability between the groups low and normal WM performers, $F(1,61)=18.572, p<.001$, partial $\eta^{2}=.235$. All other measures did not reach significance.

All data on the WM training pre-, post and follow-up measures are provided in Table 2. The ANCOVA of the WM Training Index scores revealed a significant difference between the two training conditions $(F(1,37)=6.50$, $p=.015, \eta^{2}=.15$ ), due to participants in the metacognitive strategy training group (MC) scoring higher than the standard WM training group.

The ANCOVA used to index change from pre-test to post-test revealed a significant difference between the groups in visuospatial WM $\left(F(2,60)=4.47, p=.016\right.$, partial $\left.\eta^{2}=.13\right)$. Post-hoc test revealed that the MC group significantly differed from the control group $\left(p=.013, \eta^{2}=.17\right)$, but not from the WM group $\left(p=.49, \eta^{2}=.03\right)$. There was no significant difference between the WM group and the control group, $\left(p=.31, \eta^{2}=.08\right)$. However, the ANCOVA used to index change from pre-test to 6-month follow-up of visuospatial WM showed no significant differences between groups.

Furthermore, the ANCOVAS showed that there were significant differences in visuospatial forward WM processing, both at posttest $\left(F(2,60)=4.61, p=.014, \eta^{2}=.133\right)$ and at 6-month-follow up $(F(2,58)=5.10, p$ $=.009, \eta^{2}=.15$ ). The post-hoc tests showed that the significant differences at posttest occurred between the MC group and the control group, $\left(p=.01, \eta^{2}=.20\right)$, while there was neither significant difference between MC and $\mathrm{WM}\left(p=.29, \eta^{2}=.05\right)$ nor between WM and the control group $\left(p=.48, \eta^{2}=.04\right)$. At 6 -month follow-up the post-hoc tests revealed that the significant difference occurred between $\mathrm{MC}$ and the control group $\left(p=.012, \eta^{2}\right.$ $=.19)$, but not between WM and the control group $\left(p=.066, \eta^{2}=.14\right)$ or between MC and WM $\left(p=.89, \eta^{2}=.01\right)$. No other post- and follow-up measures reached significance (see Table 2), indicating that transfer to school-related skills like arithmetics and reading and writing skills did not occur.

Table 2. Unadjusted means and standard deviations at T1 (pretest), T2 (posttest) and T3 (6-month follow-up) for the two training groups and the control group, with pairwise comparisons

\begin{tabular}{|c|c|c|c|c|c|c|c|c|c|c|c|}
\hline & \multicolumn{3}{|c|}{$\begin{array}{l}\text { Working Memory } \\
\text { group (WM) }\end{array}$} & \multicolumn{3}{|c|}{$\begin{array}{l}\text { Metacognitive WM } \\
\text { group (MC) }\end{array}$} & \multicolumn{3}{|c|}{ Control group } & \multicolumn{2}{|c|}{$\begin{array}{l}\text { Pairwise } \\
\text { comparisons }\end{array}$} \\
\hline & $\mathrm{T} 1$ & $\mathrm{~T} 2$ & $\mathrm{~T} 3$ & $\mathrm{~T} 1$ & $\mathrm{~T} 2$ & $\mathrm{~T} 3$ & $\mathrm{~T} 1$ & $\mathrm{~T} 2$ & $\mathrm{~T} 3$ & $\mathrm{~T} 1-\mathrm{T} 2$ & $\mathrm{~T} 1-\mathrm{T} 3$ \\
\hline Training Index & $\begin{array}{c}60.70 \\
(10.67)\end{array}$ & $\begin{array}{l}78.66 \\
(12.14)\end{array}$ & $\begin{array}{l}- \\
-\end{array}$ & $\begin{array}{r}62.09 \\
(10.21)\end{array}$ & $\begin{array}{c}86.04 \\
(10.22)\end{array}$ & $\begin{array}{l}- \\
-\end{array}$ & $\begin{array}{l}- \\
-\end{array}$ & $\begin{array}{l}- \\
-\end{array}$ & $\begin{array}{l}- \\
-\end{array}$ & $\mathrm{B}>\mathrm{A} *$ & - \\
\hline Raven Matrices & $\begin{array}{l}26.80 \\
(5.41)\end{array}$ & $\begin{array}{l}28.40 \\
(5.65)\end{array}$ & $\begin{array}{l}30.65 \\
(4.84)\end{array}$ & $\begin{array}{l}24.70 \\
(4.31)\end{array}$ & $\begin{array}{l}27.00 \\
(4.67)\end{array}$ & $\begin{array}{l}29.17 \\
(4.79)\end{array}$ & $\begin{array}{l}25.42 \\
(5.17)\end{array}$ & $\begin{array}{l}27.83 \\
(5.27)\end{array}$ & $\begin{array}{l}29.13 \\
(5.25)\end{array}$ & $n s$ & $n s$ \\
\hline Block design & $\begin{array}{c}31.15 \\
(13.66)\end{array}$ & $\begin{array}{l}34.20 \\
(12.87)\end{array}$ & $\begin{array}{c}40.55 \\
(11.27)\end{array}$ & $\begin{array}{c}24.15 \\
(10.26)\end{array}$ & $\begin{array}{l}29.80 \\
(14.77)\end{array}$ & $\begin{array}{c}35.50 \\
(14.91)\end{array}$ & $\begin{array}{c}27.13 \\
(12.29)\end{array}$ & $\begin{array}{c}33.21 \\
(12.52)\end{array}$ & $\begin{array}{l}33.96 \\
(13.91)\end{array}$ & $n s$ & $n s$ \\
\hline Auditory WM & $\begin{array}{l}9.05 \\
(1.50)\end{array}$ & $\begin{array}{l}10.50 \\
(2.46)\end{array}$ & $\begin{array}{c}11.20 \\
1.95\end{array}$ & $\begin{array}{c}8.60 \\
(1.19)\end{array}$ & $\begin{array}{c}9.75 \\
(2.00)\end{array}$ & $\begin{array}{l}10.50 \\
(1.69)\end{array}$ & $\begin{array}{c}9.13 \\
(1.42)\end{array}$ & $\begin{array}{c}9.79 \\
(1.87)\end{array}$ & $\begin{array}{l}10.46 \\
(1.38)\end{array}$ & $n s$ & $n s$ \\
\hline
\end{tabular}




\begin{tabular}{|c|c|c|c|c|c|c|c|c|c|c|c|}
\hline Auditory WM fw & $\begin{array}{c}6.00 \\
(1.03)\end{array}$ & $\begin{array}{c}7.05 \\
(1.57)\end{array}$ & $\begin{array}{c}7.00 \\
(1.21)\end{array}$ & $\begin{array}{c}5.45 \\
(1.23)\end{array}$ & $\begin{array}{c}6.20 \\
(1.61)\end{array}$ & $\begin{array}{c}6.39 \\
(1.50)\end{array}$ & $\begin{array}{c}5.92 \\
(1.14)\end{array}$ & $\begin{array}{c}6.46 \\
(1.44)\end{array}$ & $\begin{array}{c}6.63 \\
(0.92)\end{array}$ & $n s$ & $n s$ \\
\hline Auditory WM bw & $\begin{array}{c}3.05 \\
(0.89)\end{array}$ & $\begin{array}{c}3.45 \\
(1.19)\end{array}$ & $\begin{array}{c}4.20 \\
(1.19)\end{array}$ & $\begin{array}{c}3.15 \\
(0.93)\end{array}$ & $\begin{array}{c}3.55 \\
(1.00)\end{array}$ & $\begin{array}{c}4.11 \\
(1.13)\end{array}$ & $\begin{array}{c}3.21 \\
(0.88)\end{array}$ & $\begin{array}{c}3.33 \\
(1.01)\end{array}$ & $\begin{array}{c}3.83 \\
(1.17)\end{array}$ & $n s$ & $n s$ \\
\hline Visuospatial WM & $\begin{array}{l}11.70 \\
(3.31)\end{array}$ & $\begin{array}{l}13.80 \\
(2,91)\end{array}$ & $\begin{array}{l}13.75 \\
(2.57)\end{array}$ & $\begin{array}{l}11.05 \\
(2.70)\end{array}$ & $\begin{array}{l}14.50 \\
(3.43)\end{array}$ & $\begin{array}{l}12.94 \\
(3.10)\end{array}$ & $\begin{array}{l}10.54 \\
(2.86)\end{array}$ & $\begin{array}{l}12.00 \\
(2.28)\end{array}$ & $\begin{array}{l}12.00 \\
(2.83)\end{array}$ & $\mathrm{B}>\mathrm{C} *$ & $n s$ \\
\hline Visuospatial WM fw & $\begin{array}{c}6.65 \\
(1.35)\end{array}$ & $\begin{array}{c}7.35 \\
(1.87)\end{array}$ & $\begin{array}{c}7.40 \\
(1.60)\end{array}$ & $\begin{array}{c}6.20 \\
(1.54)\end{array}$ & $\begin{array}{c}8.10 \\
(1.83)\end{array}$ & $\begin{array}{c}7.50 \\
(1.82)\end{array}$ & $\begin{array}{c}5.96 \\
(1.57)\end{array}$ & $\begin{array}{c}6.50 \\
(1.41)\end{array}$ & $\begin{array}{c}6.04 \\
(1.40)\end{array}$ & $\mathrm{B}>\mathrm{C} *$ & $\mathrm{~B}>\mathrm{C} * *$ \\
\hline Visuospatial WM bw & $\begin{array}{c}5.05 \\
(2.44)\end{array}$ & $\begin{array}{c}6.45 \\
(1.28)\end{array}$ & $\begin{array}{c}6.35 \\
(1.46)\end{array}$ & $\begin{array}{c}4.85 \\
(1.98)\end{array}$ & $\begin{array}{c}6.40 \\
(2.23)\end{array}$ & $\begin{array}{c}5.44 \\
(1.92)\end{array}$ & $\begin{array}{c}4.58 \\
(1.64)\end{array}$ & $\begin{array}{c}5.50 \\
(1.53)\end{array}$ & $\begin{array}{c}5.96 \\
(1.85)\end{array}$ & $n s$ & $n s$ \\
\hline Arithmetics & $\begin{array}{c}12.85 \\
(1.98)\end{array}$ & $\begin{array}{l}13.65 \\
(2.41)\end{array}$ & $\begin{array}{l}14.95 \\
(1.70)\end{array}$ & $\begin{array}{c}12.10 \\
(1.41)\end{array}$ & $\begin{array}{l}13.55 \\
(2.04)\end{array}$ & $\begin{array}{l}13.94 \\
(2.29)\end{array}$ & $\begin{array}{l}12.33 \\
(1.97)\end{array}$ & $\begin{array}{c}13.50 \\
(1.67)\end{array}$ & $\begin{array}{c}14.33 \\
(1.97)\end{array}$ & $n s$ & $n s$ \\
\hline Reading ability & $\begin{array}{c}7.35 \\
(4.44)\end{array}$ & $\begin{array}{c}8.05 \\
(4.62)\end{array}$ & $\begin{array}{l}10.60 \\
(4.22)\end{array}$ & $\begin{array}{c}7.00 \\
(4.63)\end{array}$ & $\begin{array}{c}7.83 \\
(4.71)\end{array}$ & $\begin{array}{c}9.58 \\
(4.23)\end{array}$ & $\begin{array}{c}4.13 \\
(3.69)\end{array}$ & $\begin{array}{c}5.46 \\
(4.44)\end{array}$ & $\begin{array}{c}7.08 \\
(4.36)\end{array}$ & $n s$ & $n s$ \\
\hline Phonological ability & $\begin{array}{l}35.00 \\
(2.41)\end{array}$ & $\begin{array}{l}35.35 \\
(2.60)\end{array}$ & $\begin{array}{l}35.35 \\
(2.16)\end{array}$ & $\begin{array}{l}33.35 \\
(4.76)\end{array}$ & $\begin{array}{l}34.94 \\
(3.81)\end{array}$ & $\begin{array}{l}35.84 \\
(3.17)\end{array}$ & $\begin{array}{l}33.08 \\
(3.78)\end{array}$ & $\begin{array}{l}34.54 \\
(4.37)\end{array}$ & $\begin{array}{c}35.83 \\
(2.82)\end{array}$ & $n s$ & $n s$ \\
\hline Word comprehension & $\begin{array}{l}11.45 \\
(2.11)\end{array}$ & $\begin{array}{l}11.90 \\
(2.83)\end{array}$ & $\begin{array}{l}12.95 \\
(2.40)\end{array}$ & $\begin{array}{c}9.00 \\
(3.49)\end{array}$ & $\begin{array}{l}10.33 \\
(2.38)\end{array}$ & $\begin{array}{l}11.26 \\
(3.05)\end{array}$ & $\begin{array}{c}9.50 \\
(2.77)\end{array}$ & $\begin{array}{l}10.75 \\
(3.83)\end{array}$ & $\begin{array}{c}11.13 \\
(3.28)\end{array}$ & $n s$ & $n s$ \\
\hline Spelling ability & $\begin{array}{l}12.70 \\
(2.39)\end{array}$ & $\begin{array}{l}12.65 \\
(2.78)\end{array}$ & $\begin{array}{l}13.95 \\
(3.03)\end{array}$ & $\begin{array}{l}11.50 \\
(4.19)\end{array}$ & $\begin{array}{l}12.89 \\
(3.14)\end{array}$ & $\begin{array}{l}13.89 \\
(3.78)\end{array}$ & $\begin{array}{l}11.62 \\
(3.88)\end{array}$ & $\begin{array}{l}12.96 \\
(3.72)\end{array}$ & $\begin{array}{c}13.33 \\
(3.90)\end{array}$ & $n s$ & $n s$ \\
\hline
\end{tabular}

$*=p<.05 ; * *=p<.01$. All measures reported as test scores, except Training Index as standard score. $f w=$ forward, bw = backward. $A=$ WM group, $B=M C$ group, $C=$ Control group.

\section{Discussion}

The aim of this study was twofold: Firstly, investigating the profiles of general cognitive ability, arithmetic ability, reading/writing skills and especially the variability of working memory functioning among typical referred sample of SEN children. Of particular interest was the prevalence of low performance in the different domains, and especially in the area of WM.

The referred group of children with SEN performed significantly lower on auditory WM than the normal population, but the majority of the children referred did not have clinically low levels of WM performance according to cutoff criteria. This is in contrast to previous research (Alloway et al., 2005) that reported significantly lower visuospatial WM in groups of children with SEN.

The study also showed that the arithmetic ability and reading and writing skills were significantly lower in the referred group. It is particularly salient that the proportion of children in the referred group with low performance ranged from remarkable 50 to 67 percent on three out of four reading and writing skills measures. Clearly, the referred group of SEN children is challenged in school related skills of mathematics and reading and writing. However, in this referred group only arithmetic ability was significantly lower among low WM performers compared to normal WM performers. Both groups show difficulties on reading and writing skills, thus indicating that the performance in these skills were not primarily related to level of WM. Since the majority of the referred group of children with SEN actually did not show clinically low levels of WM it could be argued that the referral and screening process to WM training should be scrutinized to a greater extent when using WM training as remediation in school.

Secondly, we wanted to examine the effects of WM training, with two training procedures, with and without metacognitive strategy training, and the transfer both to general cognitive and WM abilities and school related skills. Important findings emerged in the analysis of WM training. First, the training effects in the metacognitive group measured during training improved compared to the standard WM training group, which is an immediate effect on the level of performance during WM training. Second, the training program had significant transfer effects to the visuospatial WM tasks, exclusively restricted to participants in the metacognitive group when compared to the control group. Interestingly, the achieved improvement in the visuospatial WM tasks appeared to be dependent on the difference in the forward WM processing, a result also maintained at the 6-month follow-up. Third, there were no effects to general cognitive ability or to the school-related skills of arithmetics 
and reading/writing skills, implying that no far transfer occurred, contrary to the findings of for example Holmes et al. (2009) and Dahlin (2010) but in line with the meta-analysis by Melby-Lervåg and Hulme (2012).

The effect observed between the metacognition group and the controls was restricted to the visuospatial WM tasks, and the forward processing in particular. This could be considered to reflect rather narrow ability of short-term WM storage component. Tentatively, one might speculate that even training of more simple cognitive functions, like WM storage are contingent of more complex cognitive and metacognitive executive higher order processes, and not merely a result of task-specific exposure and training. This would be in line with Engle and Kane (2004) stressing complex executive attention processes in WM capacity, as well as Unsworth et al. (2009) pointing to the interdependence between simple WM storage and executive processes.

The transfer effect to visuospatial WM is to some extent in line with previous research including working memory training of preschool and school children (Holmes et al., 2009; Morrison \& Chein, 2010; Thorell et al., 2009) and in children with ADHD (Holmes et al., 2010; Klingberg et al., 2002). It is also consistent with some findings from the meta-analytic study (Melby-Lervåg \& Hulme, 2012), suggesting that training effects take place predominantly in the visuospatial WM. The effects could also be explained by the content of the computer-based WM training program, which in large consists of recurring visuospatial elements in the training tasks (even in the relative few exercises where auditory WM components are involved). Furthermore, the metacognitive strategy training began with visual exploration of tasks, thereby stressing the visual elements. Given the fact that the children in the referred group had low auditory WM profiles, it could be argued that there is a need of more sensitive tailoring of WM training in terms of modality (auditory and visuospatial).

The transfer effects were only observed in forward WM processing and not in backward processing, which could be due to the fact that the latter may require more elaborate strategies and executive functions and therefore demand more thorough and teacher-guided analysis of the tasks and strategies than was provided in the metacognitive strategy training in this study. The amount of time spent on metacognitive strategy training was rather limited, and more time and effort may be needed in order to develop strategies for complex higher order tasks.

It is still interesting that there is a clear improvement and transfer to forward WM processing and that it was mediated by the effect on the immediate performance during training, as seen in the training index, which supports the importance of activating metacognitive and executive strategies during training conditions. It would be worthwhile to further study the process during the metacognitive strategy-training lessons and more specifically the prevalence and types of cognitive and metacognitive strategies, but also the interaction between the teacher and the children.

In a study of clinical and special educational practices for SEN children, Lebeer et al. (2012) pointed out that both assessment and interventions for children with SEN too often are carried out statically with little focus on how to enhance contextual factors like the metacognitive aspects. The training conditions in the standard WM training format studied lacks a systematic activation of cognitive and metacognitive strategies. One could also argue that one factor precisely affecting the inconsistent results of WM training shown in meta-analyses of previous research (Melby-Lervåg \& Hulme, 2012) might be the lack of systematic enhancement of the training conditions. In absence of systematic metacognitive strategy training, only children who already possess a vast array of cognitive and metacognitive strategies will benefit from training.

The study had some limitations. Even though the MC group significantly differed from the control group at a reasonably high magnitude of effect, the sample size was small which could explain the absence of significant effects in the WM group. It is important to recognize that there might also be considerable variability in how children respond to WM training. A number of factors might contribute to this variability, such as, the levels of verbal and conceptual understanding of strategies and previous use of cognitive and metacognitive strategies. However, in this study, to compensate for individual differences a small group setting made it possible for children to take part of and make use of different strategies with teacher guidance and in collaboration with peers. The children who received metacognitive strategy training also received more training per se. However, the children in the metacognitive training condition were not exposed to an active and increasingly challenging training of WM, and therefore the passive viewing of stimuli during the metacognitive strategy training was unlikely to contribute to the training effect. In addition, previous research has shown that training with a passive "low-dose" version did not yield significant training effects compared to an active version of the computer-training program (Klingberg et al., 2005).

In the present context, it is interesting to note that the concepts of WM, executive functions and metacognition may be particularly difficult to study since these concepts are intertwined (Hofmann, Friese, Schmeichel, \& 
Baddeley, 2010), even the more in applied educational settings. Developing cognitive and metacognitive strategies involves also WM processing of these strategies. Both cognitive strategies and metacognitive strategies are part of verbal and conceptual content in WM processing. It is therefore difficult to control the relation between WM and the use of task-oriented cognitive strategies and metacognitive strategies in an applied school setting since these phenomena are nested and overlapping. With these complex circumstances in mind our study still showed that by adopting a metacognitive strategy during training, the effects of WM training could be enhanced in a school environment.

To summarize, the results suggest that in referral to WM training, the remediation to a greater degree should be customized to specific WM profiles of children. This calls for development of both assessment procedures and inclusion criteria for WM training in schools, as well as tailoring of WM training programs in terms of emphasis in visuospatial and auditory WM. The results also indicate that metacognitive strategy training was a necessary addition in order to obtain effects following the WM training, thus suggesting that more complex metacognitive strategies and executive functions should be adressed in WM training. Future research should focus on delineating how different types of training regimens tailored to school settings can affect and enhance cognitive functioning, which, in turn, could generalize into more optimal learning environments for children with SEN. It is also of importance to continue to elaborate on the relation between task-specific cognitive and more domain-general metacognitive and executive strategies, and their respective place in applied interventions in school in general, and in remediation for children with SEN in particular.

\section{References}

Alloway, T. P., Gathercole, S. E., \& Pickering, S. J. (2006). Verbal and visuospatial short-term and working memory in children: Are they separable? Child Development, 77, 1698-1716. http://dx.doi.org/10.1111/j.1467-8624.2006.00968.x

Alloway, T. P., Gathercole, S. E., Adams, A. M., \& Willis, C. (2005). Working memory abilities in children with special educational needs. British Psychological Society.

Autin, F., \& Croizet, J.-C. (2012). Improving working memory efficiency by reframing metacognitive interpretation of task difficulty. Journal of Experimental Psychology: General, 141(4), 610-618. http://dx.doi.org/10.1037/a0027478

Baddeley, A. D. (1986). Working Memory. Oxford: Oxford University Press.

Baddeley, A. D. (2007). Working memory, thought and action. OUP Oxford.

Boer, H., de., Donker-Bergstra, A. S., Kostons, D. D. N. M., Korpershoek, H., \& van der Werf, M. P. (2013). Effective Strategies for Self-regulated Learning: A Meta-Analysis. GION/RUG.

Borkowski, J. G., Estrada, M. T., Milstead, M., \& Hale, C. A. (1989). General problem-solving skills: Relations between metacognition and strategic processing. Learning Disability Quarterly, 12(1), 57-70. http://dx.doi.org/10.2307/1510252

Carretti, B., Borella, E., \& De Beni, R. (2007). Does Strategic Memory Training Improve the Working Memory Performance of Younger and Older Adults? Experimental Psychology, 54(4), 311-320. http://dx.doi.org/10.1027/1618-3169.54.4.311

Cogmed. (2009). Cogmed coaching manual. Cogmed. Retrieved from http://www.cogmed.com

Cohen, J. (1988). Statistical power analysis for the behavioral sciences (2nd ed.). Hillsdale, NJ7 Lawrence Erlbaum.

Cowan, N. (2012). Working memory capacity. Psychology press.

Dahlin, K. (2010). Effects of working memory training on reading in children with special needs. Reading and Writing, 24(4), 479-491. http://dx.doi.org/10.1007/s11145-010-9238-y

Das, J. P., Naglieri, J. A., \& Kirby, J. R. (1994). Assessment of cognitive processes. Boston: Allyn \& Bacon.

Das, J. P. (1999). PREP: PASS Reading Enhancement Program. Deal NJ: Sarka Educational Resources.

Engle, R. W., \& Kane, M. J. (2004). Executive attention, working memory capacity, and a two-factor theory of cognitive control. Psychology of learning and motivation, 44, 145-200. http://dx.doi.org/10.1016/S0079-7421(03)44005-X

Fenesi, B., Sana, F., Kim, J. A., \& Shore, D. I. (2014). Reconceptualizing Working Memory in Educational Research. Educational Psychology Review, 27(2), 333-351. http://dx.doi.org/10.1007/s10648-014-9286-y 
Feuerstein, R., Rand, Y., Hoffman, M. B., \& Miller, R. (1980, 2004). Instrumental enrichment: An intervention program for cognitive modifiability. Baltimore, MD: University Park Press.

Flavell, J. H. (1976). Metacognitive aspects of problem solving. In L. B. Resnick (Ed.), The nature of intelligence (pp. 231-236). Hillsdale, NJ: Erlbaum.

Flavell, J. H. (1979). Metacognition and cognitive monitoring. A new area of cognitive development inquiry. American Psychologist, 34, 906-911.

Fletcher, J. M., Francis, D. J., Shaywitz, S. E., Lyon, G. R., Foorman, B. R., ... Steubing, K. K. (1998). Intelligent testing and the discrepancy model for children with learning disabilities. Learning Disabilities Research and Practice, 13, 186-203.

Hattie, J., Biggs, J., \& Purdie, N. (1996). Effects of learning skills interventions on student learning: A $\begin{array}{lllll}\text { meta-analysis. } & \text { Review of educational research, 66(2), 99-136. }\end{array}$ http://dx.doi.org/10.3102/00346543066002099

Hofmann, W., Friese, M., Schmeichel, B. J., \& Baddeley, A. D. (2011). Working memory and self-regulation. In K. D. Vohs, \& R. F. Baumeister (Eds.), Handbook of Self-Regulation: Research, Theory, and Applications (Vol. 2, pp. 204-225). New York: Guilford Press.

Holmes, J., Gathercole, S. E., \& Dunning, D. L. (2009). Adaptive training leads to sustained enhancement of poor working memory in children. Developmental Science, 12(4), 9-15. http://dx.doi.org/10.1111/j.1467-7687.2009.00848.x

Holmes, J., Gathercole, S. E., Place, M., Dunning, D., Hilton, K., \& Elliott, J. (2010). Working memory deficits can be overcome: Impacts of training and medication on working memory in children with ADHD. Applied Cognitive Psychology, 24, 827-836. http://dx.doi.org/10.1002/acp.1589

Järpsten, B., \& Taube, K. (1997). DLS-handledning för klasserna 2-3 [Diagnostics of Reading and Writing Abilities]. Stockholm: Psykologiförlaget.

Kail, R., \& Hall, L. K. (2001). Distinguishing short-term memory from working memory. Memory \& Cognition, 29, 1-9. http://dx.doi.org/10.3758/BF03195735

Klingberg, T., Fernell, E., Olesen, P. J., Johnson, M., Gustafsson, P., ... Dahlström, K. (2005). Computerized training of working memory in children with ADHD-A randomized controlled trial. Journal of the American Academy of Child and Adolescent Psychiatry, 44(2), 177-186. http://dx.doi.org/10.1097/00004583-200502000-00010

Klingberg T., Forssberg, H., \& Westerberg, H. (2002). Training of Working Memory in Children with ADHD. Journal of Clinical and Experimental Neuropsychology, 24(6), 781-791. http://dx.doi.org/10.1076/jcen.24.6.781.8395

Klingberg, T. (2010). Training and plasticity of working memory. Trends in cognitive sciences, 14(7), 317-324. http://dx.doi.org/10.1016/j.tics.2010.05.002

Lebeer, J., Birta-Székely, N., Demeter, K., Bohács, K., Araujo Candeias, A., Sønnesyn, G., ... \& Dawson, L. (2012). Re-assessing the current assessment practice of children with special education needs in Europe. School Psychology International, 33(1), 69-92. http://dx.doi.org/10.1177/0143034311409975

Mayes, S. D., Calhoun, S. L., \& Crowell, E. W. (1998). WISC-III profiles for children with and without learning disabilities. Psychology in the Schools, 35, 309-316.

Melby-Lervåg, M., \& Hulme, C. (2012). Is working memory training effective? A meta-analytic review. Developmental Psychology. http://dx.doi.org/10.1037/a0028228

McNamara, D. S., \& Scott, J. L. (2001).Working memory capacity and strategy use. Memory and Cognition, 29 , 10-17. http://dx.doi.org/10.3758/BF03195736

Mevarech, Z. R. (1999). Effects of metacognitive training embedded in cooperative settings on mathematical problem solving. Journal of Educational Research, 92(4), 195-205. http://dx.doi.org/10.1080/00220679909597597

Morrison, A., \& Chein, J. (2011). Does working memory training work? The promise and challenges of enhancing cognition by training working memory. Psychonomic Bulletin \& Review, 18, 46-60. http://dx.doi.org/10.3758/s13423-010-0034-0

Naglieri, J. A., \& Johnson, D. (2000). Effectiveness of a cognitive strategy intervention in improving arithmetic 
computation based on the PASS theory. Journal of learning disabilities, 33(6), 591-597. http://dx.doi.org/10.1177/002221940003300607

Passolunghi, M. C., \& Siegel, L. S. (2001). Short-term memory, working memory, and inhibitory control in children with difficulties in arithmetic problem solving. Journal of experimental child psychology, $80(1)$, 44-57. http://dx.doi.org/10.1006/jecp.2000.2626

Passolunghi, M. C., \& Siegel, L. (2004). Working memory and access to numerical information in children with disability in mathematics. Journal of Experimental Child Psychology, 88, 348-367. http://dx.doi.org/10.1016/j.jecp.2004.04.002

Pickering, S. J., \& Gathercole, S. E. (2004). Distinctive working memory profiles in children with special $\begin{array}{llll}\text { educational needs. } & \text { Educational }\end{array}$ http://dx.doi.org/10.1080/0144341042000211715

Raven, J. C. (1995). Coloured Progressive Matrices. Oxford, United Kingdom: Oxford Psychologists Press.

Signeuric, A., Ehrlich, M. F., Oakhill, J. V., \& Yuill, N. M. (2000). Working memory resources and children's reading comprehension. Reading and writing, 13(1-2), 81-103.

Swanson, H. L. (1994). Short-Term Memory and Working Memory Do Both Contribute to Our Understanding of Academic Achievement in Children and Adults with Learning Disabilities? Journal of Learning disabilities, 27(1), 34-50. http://dx.doi.org/10.1177/002221949402700107

Swanson, H. L., Howard, C. B., \& Sáez, L. (2006). Do different components of working memory underlie different subgroups of reading disabilities? Journal of Learning Disabilities, 39(3), 252-269. http://dx.doi.org/10.1177/00222194060390030501

Teong, S. K. (2003). The effect of metacognitive training on mathematical word-problem solving. Journal of Computer Assisted Learning, 19, 46-55. http://dx.doi.org/10.1046/j.0266-4909.2003.00005.x

Thorell, L. B., Lindqvist S., Bergman S., Bohlin G., \& Klingberg T. (2009). Training and transfer effects of executive functions in preschool children. Developmental Science, 12(1), 106-113. http://dx.doi.org/10.1111/j.1467-7687.2008.00745.x

Turley-Ames, K. J., \& Whitfield, M. M. (2003). Strategy training and working memory task performance. Journal of Memory and Language, 49, 446-468. http://dx.doi.org/10.1016/S0749-596X(03)00095-0

Tzuriel, D., Kaniel, S., Kanner, E., \& Haywood, H. C. (1999). The effectiveness of Bright Start program in kindergarten on transfer abilities and academic achievements. Early Childhood Research Quarterly, 114, 111-141.

Unsworth, N., Redick, T. S., Heitz, R. P., Broadway, J. M., \& Engle, R. W. (2009). Complex working memory span tasks and higher-order cognition: A latent-variable analysis of the relationship between processing and storage. Memory, 17(6), 635-654. http://dx.doi.org/10.1080/09658210902998047

Wechsler, D. (1991). Wechsler Intelligence Scale for Children (3rd ed.). New York: Psychological Corporation.

Wechsler, D. (2006). Wechsler Nonverbal Scale of Ability: WNV. PsychCorp.

Whitebread, D. (1999). Interactions between children's metacognitive processes, working memory, choice of strategies and performance during problem-solving. European Journal of Psychology of Education, 14(4), 489-507.

\section{Copyrights}

Copyright for this article is retained by the author(s), with first publication rights granted to the journal.

This is an open-access article distributed under the terms and conditions of the Creative Commons Attribution license (http://creativecommons.org/licenses/by/3.0/). 